(RESEARCH ARTICLE)

\title{
Promising active bioinsecticides produced by Bacillus thuringiensis strain BLB427
}

\author{
Hanen Boukedi 1, \#, Mariam Hmani 1, \#, Saoussen Ben Khedher ${ }^{1}$, Slim Tounsi ${ }^{1}$ and Lobna Abdelkefi-Mesrati 2, 3, * \\ ${ }^{1}$ Laboratory of Biopesticides, Centre of Biotechnology of Sfax, 3018 Sfax, Tunisia \\ 2 Department of Biology, Faculty of Sciences and Arts-Khulais, University of Jeddah, Saudi Arabia \\ ${ }^{3}$ Higher Institute of Biotechnology of Sfax, University of Sfax, Tunisia. \\ \# These authors contributed equally to this work.
}

Publication history: Received on 20 September 2020; revised on 27 September 2020; accepted on 29 September 2020

Article DOI: https://doi.org/10.30574/wjarr.2020.8.1.0358

\begin{abstract}
Bacillus thuringiensis is gaining worldwide importance in the control of pests in agriculture and public health. Characterization of new isolated strains with original, higher and broader spectrum of activity is an ever developing field. Parasporal inclusions from BLB427, a new B. thuringiensis strain isolated from Tunisian soil, contained 2 major Cry proteins having molecular weights of about 130-135 kDa and 65-70 kDa corresponding to cry1-type and cry2-type genes, respectively. These toxins exhibited high toxicities to Ephestia kuehniella and Spodoptera littoralis larvae, with $\mathrm{LC}_{50}$ values of about $81.91 \mu \mathrm{g} / \mathrm{cm}^{2}(+/-15.30)$ and $79.70 \mu \mathrm{g} / \mathrm{cm}^{2}(+/-36.73)$, respectively. BLB427 supernatant showed a promising activity against Lepidopteran pests due to the presence of vip3-type gene in this strain. The high toxicity of BLB427 supernatant compared to that of BUPM95, used as control, was due in part to the high copy number of vip3 gene of BLB427 compared to that of vip3Aa16 of BUPM95, as demonstrated by Real-time PCR. This gene was cloned, sequenced and the comparison with the most known vip3 genes in databases, demonstrated that vip3(427) gene and the corresponding protein showed differences that can influence the efficiency of the Vip3(427) toxin against Lepidoptera. After overexpression of Vip3(427) protein in Esherichia coli and its purification using His-Trap column, the toxin showed a promising toxicity against the lepidopteran pest $S$. littoralis with extremely damages in the larvae midgut traduced by the vacuolization of the apical cells, the damage of microvilli and the disruption of epithelial cells. The results described in the present study proved that B. thuringiensis BLB427 strain could be of a great interest for lepidopteran biocontrol by using its $\delta$-endotoxins and/or Vip3 toxins in bioinsecticides formulations.
\end{abstract}

Keywords: Bacillus thuringiensis; biocontrol; Delta-endotoxins; Vip3; Ephestia kuehniella; Spodoptera littoralis.

\section{Introduction}

Biomolecules derived from Bacillus thuringiensis are gaining worldwide importance as environmentally desirable alternatives to synthetic chemicals for pests control in public health and agriculture [1]. This Gram-positif soil bacterium is known by its ability to produce crystalline inclusions during sporulation. These parasporal inclusions are solubilized in the midgut of the target larvae, releasing proteins called $\delta$-endotoxins (or Cry) that, upon proteolytic activation, exhibit a highly specific insecticidal activity [2-4].

A second family of insecticidal proteins produced by this bacterium during its vegetative stage of growth has been identified [5]. The Vegetative insecticidal proteins (Vip) have been classified into three groups according to their sequence homology: Vip1 and Vip2 proteins that act as binary toxin and are toxic to Coleoptera [6] and Vip3 proteins known by their activity against Lepidoptera [7].

\footnotetext{
* Corresponding author: Lobna Abdelkefi-Mesrati; E. mail: mesratilobna@yahoo.com

Department of Biology, Faculty of Sciences and Arts-Khulais, University of Jeddah, Saudi Arabia. 
Due to their high efficiency in the biological control of pests, the repetitive use of some Cry toxins contributed to the resistance emergence to these Cry proteins in some insect populations. As example, we cited the resistance of Heliothis virescens to Cry1Ac and Cry2Aa toxins, and the resistance of the diamondback moth Plutella xylostella to Cry1Ac [8, 9].

The use of Vip3 toxins in combination with Cry proteins can be classified as a good strategy to ovoid these problems of resistance emergence. In fact, one of the interesting features of the Vip3 protein is that it shares no sequence homology with the $\delta$-endotoxins [7]. Moreover, in ligand blotting experiments with brush border membrane vesicles from the tobacco hornworm, Manduca sexta, activated Cry1Ab and Vip3A bound to different molecules receptors which demonstrated that resistant pests to Cry toxins can be killed by the second type of bioinsecticide (Vip3).

Moreover, isolation of new B. thuringiensis strains and cloning of novel insecticidal protein genes (cry and vip) are imperative for increasing the diversity of toxins and overcoming potential problems associated with resistance.

In the present study, we characterized a new isolated B. thuringiensis strain, named BLB427 [10], having a promising future as a biological control agent. In fact, Cry and Vip3 proteins of BLB427 demonstrated an interesting activity against different lepidopteran pests such as Ephestia kuehniella and Spodoptera littoralis.

\section{Material and methods}

\subsection{Bacterial strains and growth conditions}

New B. thuringiensis isolate BLB427 was obtained from Tunisian bioinsecticide-free soil sample [10]. B. thuringiensis BUPM95 [11] and B. thuringiensis subsp. kurstaki HD1 [12] were used as reference strains. For laboratory routine use, B. thuringiensis strains were grown in Luria-Bertani medium (LB) [13] at optimum conditions $\left(30^{\circ} \mathrm{C}, 200 \mathrm{rpm}\right) . \mathrm{T} 3$ medium [14] was used to detect the parasporal crystals formed during B. thuringiensis growth.

During the vegetative stage of $B$. thuringiensis growth and in order to promote protein production, cells were grown in PY Broth [1.2\% (w/v) peptone, 2.4\% (w/v) yeast extract, $0.4 \%(\mathrm{v} / \mathrm{v})$ glycerol, $54 \mathrm{mM} \mathrm{K}_{2} \mathrm{HPO}_{4}$ and $\left.16 \mathrm{mM} \mathrm{KH}_{2} \mathrm{PO}_{4}\right]$ [15] at optimum temperature then the culture was centrifuged and the supernatant was used for bioassays against Lepidopteran pests.

\subsection{B. thuringiensis crystal solubilization and protein content}

Total spores and crystals from B. thuringiensis strains were treated as reported by Saadaoui et al. [16]. The solubilized proteins were then analyzed by sodium dodecyl sulfate poly-acrylamide gel electrophoresis (10\% SDS-PAGE) and visualized by Coomassie blue staining [17].

\subsection{Protein quantification}

The concentrations of $B$. thuringiensis solubilized crystal proteins and purified Vip3 toxins were measured with the Bradford assay (Bio-Rad), using bovine serum albumin as a standard.

\subsection{Bioassays against Lepidopteran larvae}

A free ingestion technique was used to evaluate the toxicity to E. kuehniella, S. littoralis and A. segetum larvae of $B$. thuringiensis crystal proteins, supernatant extracts and purified Vip3(427) protein as described by Abdelkefi-Mesrati et al. [18, 19] ; Ben Hamadou-Charfi et al. [20] and Boukedi et al. [10, 21]. All the experiments were done in triplicate in the presence of a negative control set maintained in the same conditions of temperature $\left(23{ }^{\circ} \mathrm{C}\right)$, relative humidity $(65 \%)$ and photoperiod (18 h light and $6 \mathrm{~h}$ dark). Larval mortality was scored after 5 days and fifty percent lethal concentrations ( $\mathrm{LC}_{50}$ ) were calculated by probit analysis using programs written in the R. language [22].

\subsection{Plasmid DNA isolation and PCR amplification}

B. thuringiensis DNA was extracted using the alkali lysis method including a lysozyme treatment step as described by Sambrook et al. [13].

For the detection of vip3-like genes, PCR reactions were done in a thermocycler "Gene Amp PCR System 2700" (Applied Biosystems) using B. thuringiensis DNA as template and (V1, V2) as primers (Table 1). 
Using B. thuringiensis DNA, iQ SYBER Green Supermix (BIORAD) and primers V13 and PS21 (Table 1), Real-time quantitative PCR reactions were accomplished to amplify vip3-type genes. The detection of the amplified products was performed with C1000 thermal cycler (Bio-Rad) during 45 cycles [23].

Table 1 Sequences of primers used in PCR.

\begin{tabular}{|l|l|l|}
\hline Primer & Sequence $(\mathbf{5} \boldsymbol{\rightarrow} \rightarrow \mathbf{3}$ ') & Reference \\
\hline VipM1 (f) & AAGATGCA*TATGAACAAGAATAATA & {$[24]$} \\
\hline VipM2 (b) & GATG*GAT CCCGATCTTACTTAATAG & {$[24]$} \\
\hline V1 (f) & ATGAACAAGAATAATACTA & {$[11]$} \\
\hline V13 (f) & CAAGCCGCAAATCTTGTGGA & {$[21]$} \\
\hline V2 (b) & TCTATTTGCAGACTTAGCGC & {$[11]$} \\
\hline V3 (b) & TTACTTAATAGAGACATCGT & {$[11]$} \\
\hline PS21 (b) & ATGGCTTGTTTCGCTACATC & {$[21]$} \\
\hline
\end{tabular}

\subsection{Cloning and sequencing of vip3-type gene}

The open reading frame (ORF) of the vip3-type gene was PCR amplified, using total DNA isolated from B. thuringiensis strain BLB427 as template, primers V1 and V3 (Table 1) and DNA polymerase (Amersham). The obtained fragment, having a molecular weight rounding $2.37 \mathrm{~kb}$, was purified from the agarose gel and the vip3 ORF was cloned in pGEMTeasy vector (Promega) generating a recombinant plasmid pGEMvip3(427). As reported by Sambrook et al. [13], E. coli cells (Top10) transformation was performed then selection of recombinant cells was performed on plates containing LB medium supplemented with ampicillin $(100 \mathrm{mg} / \mathrm{ml}), 5$-bromo-4-chloro-3-indolyl $\beta$-D-galactoside $(40 \mathrm{mg} / \mathrm{ml})$ and Isopropyl $\beta$-D-thiogalactoside $(80 \mathrm{mg} / \mathrm{ml})$.

The vip3(427) gene sequencing was carried out using a recombinant plasmid, the taq DyeDeoxy Terminator Cycle Sequencing kit and a 3700 ABI Prism DNA sequencer (Applied Biosystems, Foster City, CA) according to the manufacturer's instructions. The sequence was subjected to a blast nucleotide homology search against the nucleotide database of the National Center for Biotechnology Information (http://www.ncbi.nlm.nih.gov/Blast.cgi).

\subsection{Over-expression of vip3(427) in Escherichia coli and protein purification}

The vip3(427) gene (GenBank Accession No. MG659728) overexpression was achieved by cloning its ORF in the pET14b vector (Novagen). As described by Abdelkefi-Mesrati et al. [24] and using VipM1 and VipM2 primers (Table 1), restriction enzyme sites NdeI and BamHI were created by PCR upstream the initiation codon (ATG) and downstream the stop codon of the gene, respectively. After being cloned into pGEM-Teasy vector (Promega), the open reading frame of the gene $(2.37 \mathrm{~kb})$ was recovered by digesting it with the restriction enzymes $N d e I$ and BamHI. Then, the gene was cloned in frame in its 5' end with the His-tag sequence of the E. coli expression vector pET-14b (Novagen) and the recombinant plasmid, named pET-vip3(427), was transformed into E. coli BL21(DE3). As described by AbdelkefiMesrati et al. [24], recombinant cells were grown in Luria-Bertani medium supplemented with ampicillin (100 mg/ml) and induced using IPTG.

The sonication of the recombinant cells was done in buffer [PBS 1X (pH 7.5); $4 \mathrm{mM}$ 4-(2-aminoethyl)-benzenesulfonyl fluoride] [24] and after centrifugation, the supernatant was loaded onto His-Trap column (Amersham) preequilibrated with a binding buffer (PBS 1X, imidazole $40 \mathrm{mM}$ ). Bound proteins were then eluted using elution buffers containing increasing concentrations of imidazole in PBS $1 \mathrm{X}$ as described by Abdelkefi-Mesrati et al. [24].

\subsection{Preparation and sectioning of insect tissues}

After exposure to the B. thuringiensis Vip3(427) toxins, lepidopteran larvae were placed in $10 \%$ formaldehyde [19]. Larvae were then dehydrated in increasing ethanol concentrations, rinsed in toluene $(100 \%)$ and embedded in paraffin wax. Sections $(5 \mu \mathrm{m})$ were obtained and placed in carriers loaded with a mix of $1.5 \%$ egg albumin and $3 \%$ glycerol in distilled water. After being de-paraffinated in $100 \%$ toluene, sections were stained with hematoxylin eosin for histopathological localization of the effects of $B$. thuringiensis Vip3 toxins on midgut larvae. 


\section{Results and discussion}

\subsection{BLB427 crystal protein content}

BLB427 is one of the promising B. thuringiensis strains isolated by Boukedi et al. [10]. This strain was characterized by a special plasmid profile compared to the collection of about 200 B. thuringiensis isolates [10]. To compare the compositions of parasporal proteins extracted from $B$. thuringiensis BLB427, BUPM95 and HD1, SDS-PAGE analysis was employed. Parasporal inclusions from BLB427 contained 2 major Cry proteins having molecular weights of about 130$135 \mathrm{kDa}$ and 65-70 kDa corresponding to cry1-type and cry2-type genes, respectively (Fig. 1). This profile was similar to that detected for BUPM95 and HD1 used as reference strains (Fig. 1) and give us an idea about the cry-type genes that BLB427 may contain and the possible efficiency of this strain to control lepidopteran pests.

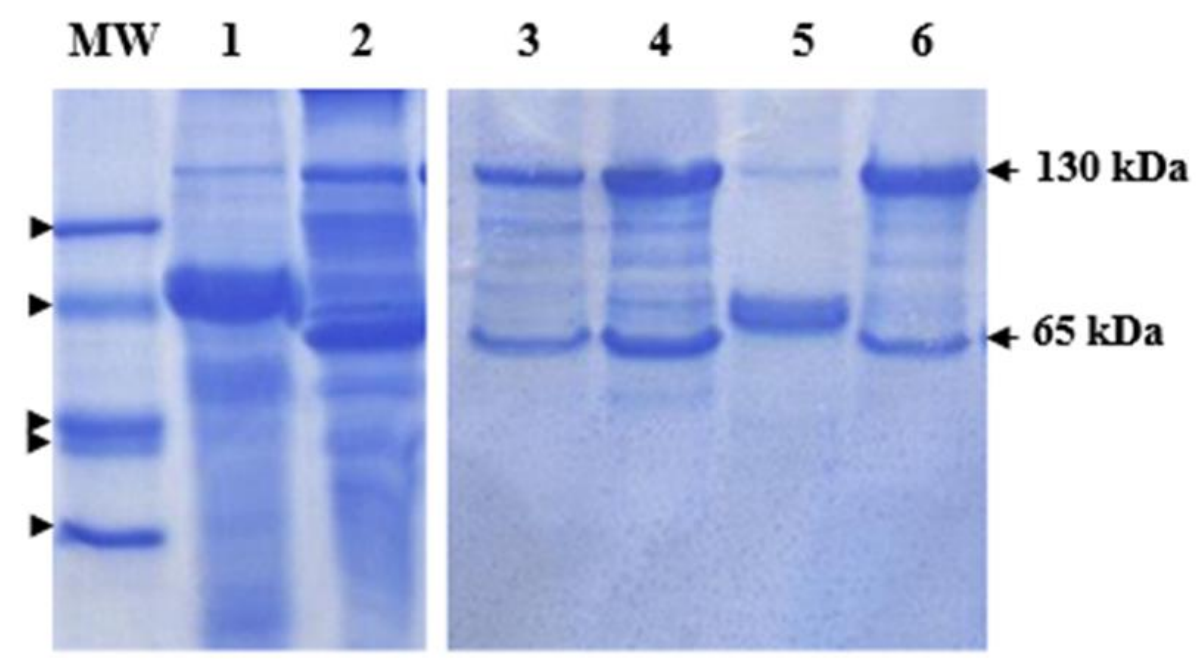

Figure 1 Analysis of $B$. thuringiensis parasporal inclusions content.

Analysis of $B$. thuringiensis proteins found in the crystal by SDS-PAGE. Lanes: MW: Molecular weight marker (97; 66; 45; 30; 20,1 kDa); 1, Crystal proteins of BLB459; 2, Crystal proteins of HD1; 3, Crystal proteins of BLB384; 4, Crystal proteins of BLB427; 5, Crystal proteins of BLB459; 6, Crystal proteins of BUPM95.

\subsection{Insecticidal activity of BLB427 delta-endotoxins against Lepidoptera}

Bioassays against lepidopteran pests were conducted using parasporal inclusions of BLB427 and HD1 as reference and the insecticidal activity was assessed using $\mathrm{LC}_{50}$ values [22]. Table 2 revealed that parasporal proteins of BLB427 exhibited high toxicities to E. kuehniella and S. littoralis larvae, with $\mathrm{LC}_{50}$ values of about $81.91 \mu \mathrm{g} / \mathrm{cm}^{2}(+/-15.30)$ and $79.70 \mu \mathrm{g} / \mathrm{cm}^{2}(+/-36.73)$, respectively. According to the results showed in Table 2, we presumed that Cry toxins of BLB427 were slightly more active against the cited Lepidoptera than those of the reference strain, HD1. This result supports the use of this strain in the biological control of Lepidoptera.

Table 2 Bacillus thuringiensis parasporal proteins efficiency against Lepidopteran larvae

\begin{tabular}{|l|c|l|}
\hline & Parasporal proteins of $B$. thuringiensis strains \\
\hline & BLB427 & HD1 \\
\hline $\begin{array}{l}\text { LC } \\
\left(\mu \mathrm{g} / \mathrm{cm}^{2} \text { of } \text { ogainst } \text { E. kuehnielina }\right)\end{array}$ & $81.91(+/-15.30)$ & $71.08(+/-11.44)$ \\
\hline $\begin{array}{l}\mathrm{LC} 50 \text { against } S . \text { littoralis } \\
\left(\mu \mathrm{g} / \mathrm{cm}^{2} \text { of artificial diet }\right)\end{array}$ & $79.70(+/-36.73)$ & $112.80(+/-12.26)$ \\
\hline
\end{tabular}




\subsection{Insecticidal activity of BLB427 supernatant}

To know if BLB427 strain produces soluble insecticidal molecules, the insecticidal activity of its supernatant against lepidopteran pests was evaluated. The Duncan grouping test performed after ANOVA analysis revealed that mortality caused by BLB427 supernatant was statistically higher than that of the reference strain B. thuringiensis BUPM95 as demonstrated in Figure 2. Moreover, the both supernatant strains are significantly more toxic against $S$. littoralis and $E$. kuehniella than $A$. segetum, according to the Duncan grouping test (Table 3 ). Some $B$. thuringiensis strains are able to secrete vegetative insecticidal proteins known by their acute activity against lepidopteran pests [7, 21]. For that, we suggested to investigate the presence of genes encoding such proteins in B. thuringiensis strain BLB427.

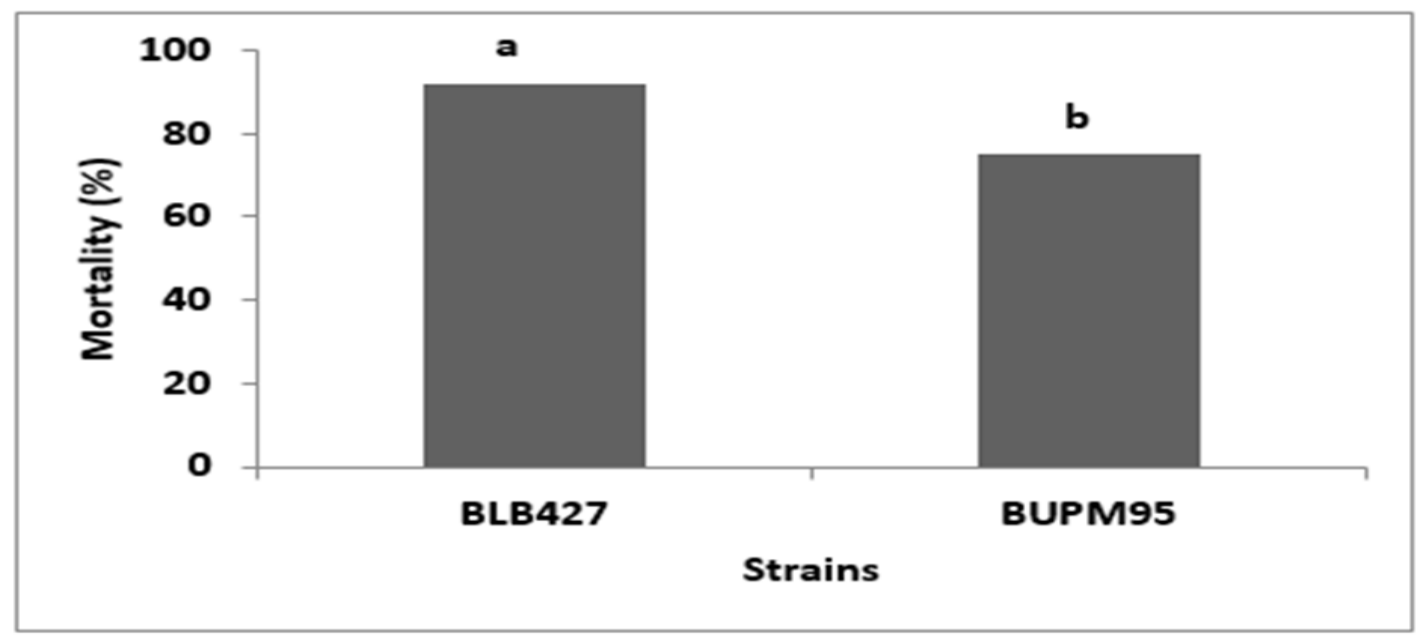

Figure 2 Means of $B$. thuringiensis supernatants efficiency against Lepidoptera.

* Means with the same letter are not significantly different, at $\mathrm{p}=0.05$ upon Duncan multiple range test.

\subsection{Evidence of vip3 gene presence in BLB427 strain (PCR and quantitative PCR)}

Using (V1, V2) primers (Table 1) and Polymerase Chain Reaction, we investigated the presence of vip3-type genes in the new isolated B. thuringiensis BLB459. And as suspected, BLB459 DNA amplification showed a fragment of about $0.4 \mathrm{~kb}$ corresponding to a vip3-type gene and demonstrated that this strain is able to produce Vip3 toxins in contrast to the negative control which did not lead to any amplification product (Data not shown). To compare the vip3-type genes copy numbers between $B$. thuringiensis BLB427 and the reference strain BUPM95 [11], we decided to amplify identical quantities of DNA extracted from each strain by Real-time quantitative PCR. As shown in figure 3, fluorescence emerged early in the case of BLB427 DNA with a threshold cycle (Ct) of about 23 (Fig. 3A) while the Ct detected for BUPM95 DNA was around 29 (Fig. 3B). The detected differences between the mean Ct values of the samples tested demonstrated that BLB427 strain contains a higher copy-number of vip3 gene than BUPM95 and such result can explain the differences in the efficiency of the supernatants of these two strains against Lepidoptera (Table 3).

Table 3 Insecticidal activities of $B$. thuringiensis supernatants.

\begin{tabular}{|l|l|l|}
\hline \multirow{2}{*}{ Larvae } & \multicolumn{2}{|l|}{ Strains } \\
\cline { 2 - 3 } & BLB427 & BUPM95 \\
\hline E. kuehniella & $93.10 \pm 3.42 \% \mathrm{a}^{*}$ & $75.30 \pm 1.044 \% \mathrm{a}$ \\
\hline S. littoralis & $95.60 \pm 0.79 \% \mathrm{a}$ & $77.40 \pm 1.70 \% \mathrm{a}$ \\
\hline A. segetum & $87.50 \pm 1.37 \% \mathrm{~b}$ & $72.50 \pm 3.57 \% \mathrm{~b}$ \\
\hline
\end{tabular}

${ }^{*}$ Means in the same column not followed by the same letters are significantly different at $\mathrm{p}=0.05$ upon Duncan multiple range test. 


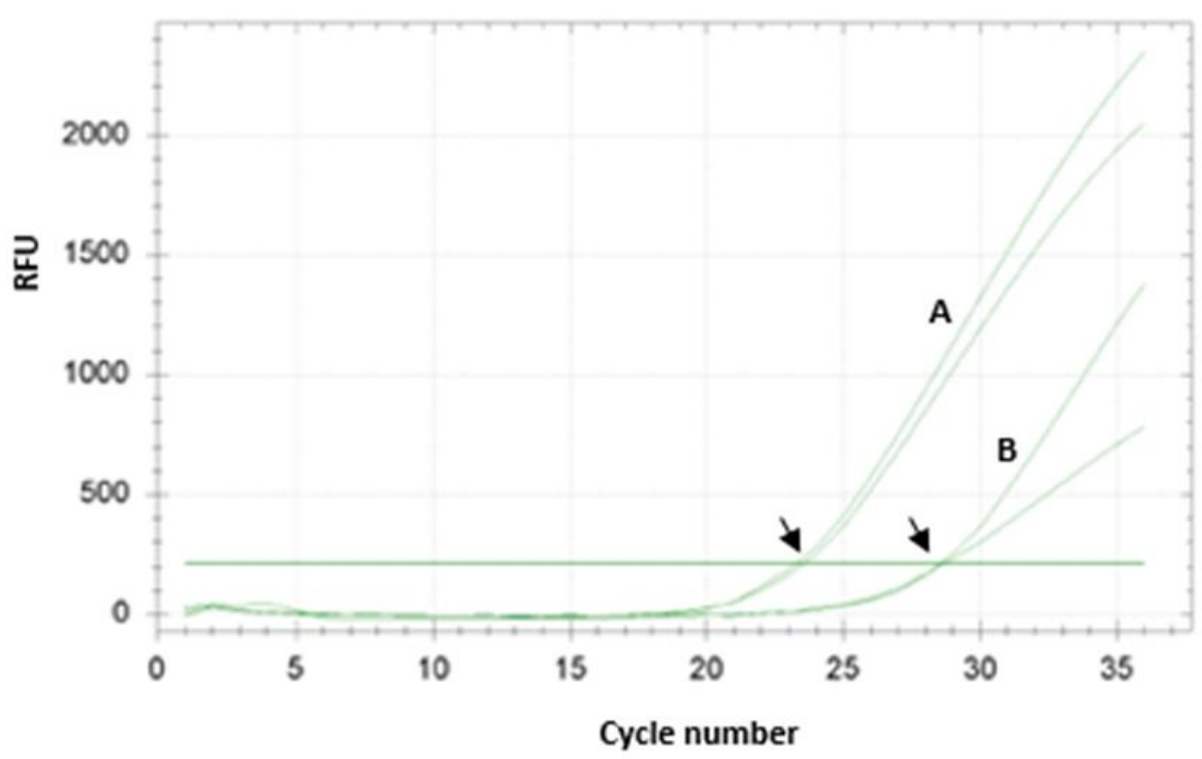

Figure 3 The amplification curves of vip3-type gene as recorded in Real-time quantitative PCR reactions. Reactions operated using DNA extracted from B. thuringiensis strains BLB427 (A) and the reference strain BUPM95 (B).

RFU: relative fluorescence units.

\subsection{Cloning and sequence analysis of the BLB427 vip3 gene}

To investigate the main reasons of the higher toxicity of BLB427 supernatant against Lepidoptera compared to that of the reference strain BUPM95, we decided to clone and sequence the vip3 gene of this isolate and compare the corresponding protein with Vip3Aa16 of B. thuringiensis BUPM95 [11]. The amplified PCR fragment corresponding to the ORF (open reading frame) of vip3(427) was cloned in the pGEMTeasy vector and the resultant recombinant plasmid was used for the vip3 gene sequencing. The obtained sequence corresponds to an ORF of 2370 pb that encodes a protein of about 789 AA residues with a predicted molecular mass rounding the $88.5 \mathrm{kDa}$. The search for sequence similarity, using Blast, demonstrated that vip3(427) harbored some differences compared to the other reported vip3 genes. This result was confirmed with multiple alignments using the program CLUSTALW. When compared with the most known vip3-type genes, there was substitutions at different positions resulting in the modification of the corresponding amino acid (Figure 4). These modifications can have positive or negative effects on the toxicity of the Vip3(427) protein against Lepidoptera. 

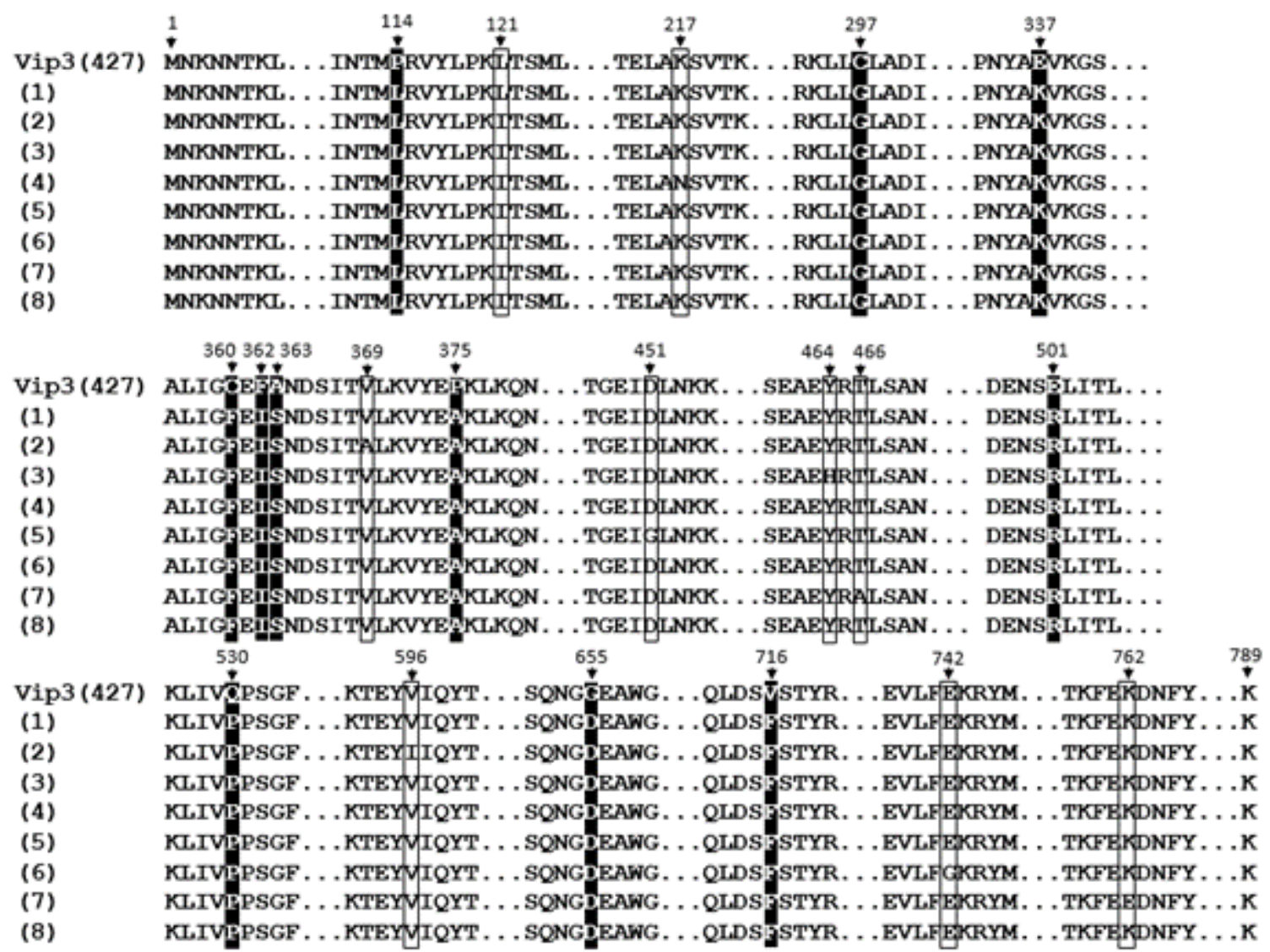

Figure 4 Comparison of the Vip3(427) amino acid sequence with those encoded by the other vip3-type genes. GenBank Accession Numbers of the vip3 genes and their corresponding proteins: 1, Vip3Aa16 (AAW65132); 2, Vip3(459) (JN990981), 3, Vip184 (AA032350.1); 4, Vip3BR (AAW62286.1); 5, Vip3 (CAI96522.1); 6, Vip3 (CAA76665.1); 7, Vip3 (AAU89707.1); 8, Vip3V (AAN60738.1).

Vertical downward arrows indicated amino acids positions, the black boxes represented the residues showing variations and only regions containing differences are presented.

\subsection{Over-expression of vip3(427) in Escherichia coli, protein purification and study of the toxin efficiency on Lepidoptera eradication}

The vip3 gene of $B$. thuringiensis strain BLB427 was cloned in the pET-14b vector as described in Material and Methods section. The recombinant strain E. coli (pET-vip3(427)) was induced by IPTG than cells were sonicated. Supernatant proteins were analyzed by SDS-PAGE and showed the presence of a protein with high amount and having a molecular weight of about $90-\mathrm{kDa}$ which corresponds to the expressed Vip3 protein. Based on the six-histidine tail fused at the Nterminal end of Vip3(427) protein, we purified the toxin using the His-trap column and an increasing gradient of imidazole.

When tested against first instar larvae of $S$. littoralis, purified Vip3(427) protein showed an interesting toxicity with an LC 50 of about $239.52(+/-41.52) \mathrm{ng} / \mathrm{cm}^{2}$. Negative control set was done by the exposure of larvae to the buffer solution and the treatment did not affect larval growth increase, weight gain, or morphology. When compared to the purified Vip3Aa16 of BUPM95 having an $\mathrm{LC}_{50}$ against $S$. littoralis of about $305(+/-95) \mathrm{ng} / \mathrm{cm}^{2}$ [19], the purified Vip3(427) was slightly more active against this lepidopteran pest. This difference can be due to the variations detected on the amino acid sequences described above.

Histological observations of Vip3(427) effects on S. littoralis were studied on first instar larvae which had been fed a diet containing the purified protein. We detected extensive damages in the midgut of larvae treated with the Vip3(427) toxin (Fig. 5B) in contrast to the negative control corresponding to the midgut of untreated larvae that showed uniform morphology with well-defined epithelial cells and unaffected apical microvilli membrane (Fig. 5A). We noticed that main histopathological modifications included brush border membrane destruction, intensive vacuolization of the cytoplasm, and vesicle secretion in the apical region of cells toward the midgut lumen (Fig. 5B). This kind of mode of action is 
similar to that described for other B. thurigiensis Vip3 toxins active against Lepidoptera such as Vip3Aa16 of B. thuringiensis BUPM95 that caused serious damages in the midgut larvae of the lepidopteran pest S. littoralis [19].
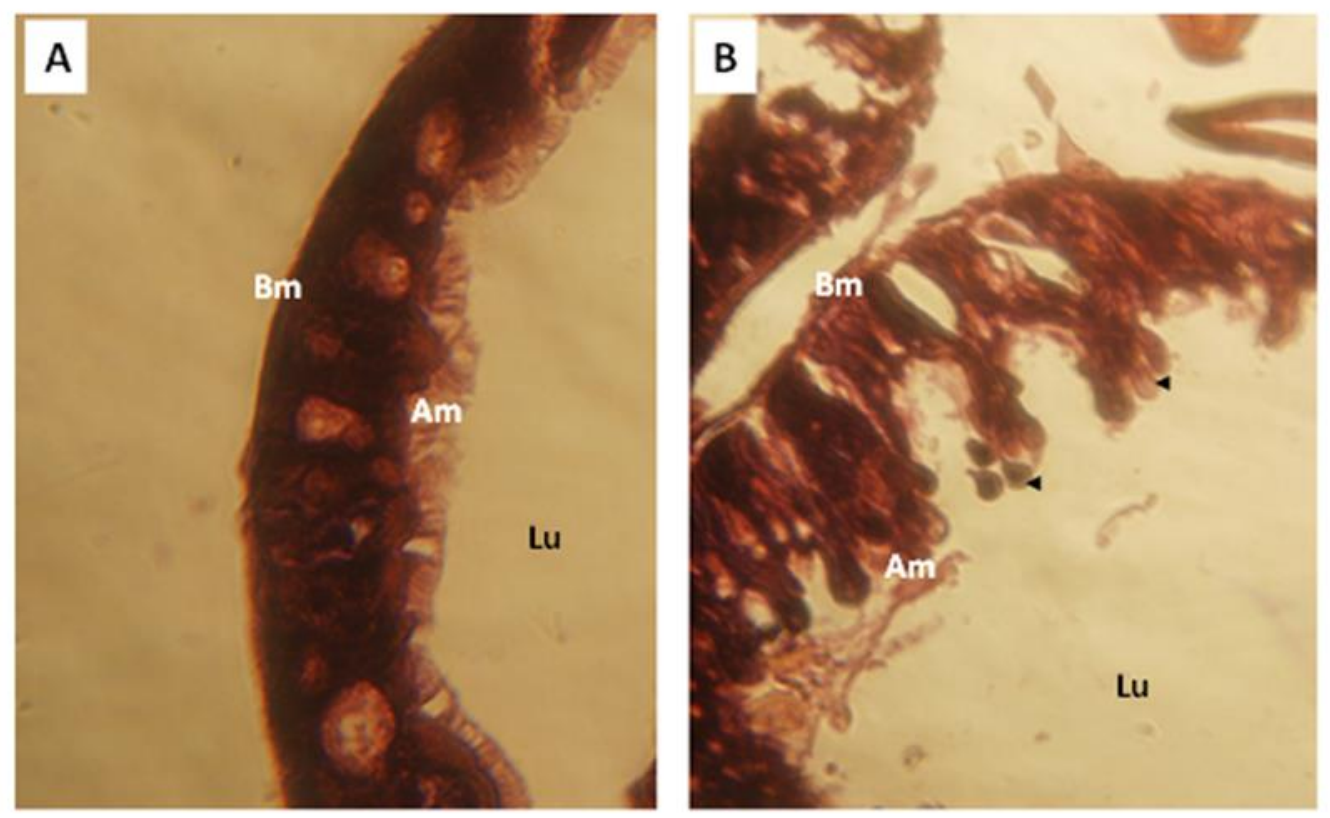

Figure 5 Histopathological effects of B. thuringiensis Vip3(427) toxin on Lepidopteran midgut larvae. A: General aspects of the midgut larvae of S. littoralis; B: Histopathological effects of purified Vip3(427) toxin on the midgut larvae of the lepidopteran pest S. littoralis. Am, Apical membrane; Bm, Basement membrane; Lu, Lumen. Magnification 40X. Arrowhead indicates vesicle formation.

\section{Conclusion}

The present study was undertaken to investigate the insecticidal potency of $B$. thuringiensis strain BLB427. Results showed that this strain is a promising bioinsecticide. In fact, BLB427 produces 2 types of insecticidal proteins, Cry and Vip3 toxins having an interesting activity against lepidopteran pests such as S. littoralis which supports their use as a biological control agent against a large spectrum of Lepidoptera especially in case of resistance emergence in the target larvae species.

\section{Compliance with ethical standards}

\section{Acknowledgments}

This work was supported by grants from the Tunisian Ministry of Higher Education and Scientific Research, Tunisia.

\section{Disclosure of conflict of interest}

The authors; Dr. Boukedi H., Dr. Hmani M., Dr. Ben Khedher S., Pr. Tounsi S. and Pr. Abdelkefi-Mesrati L. have declared that there is no conflict of interest with the publication of this manuscript, institution as well as product that is mentioned in the manuscript.

\section{References}

[1] Van Frankenhuyzen K. The Challenge of Bacillus thuringiensis. In: Bacillus thuringiensis, An Environmental Biopesticide: Theory and Practice (Entwistle, P.E., Cory, J.S., Bailey, M.J. and Higgs, S., Eds.), Chichester, UK, John Wiley \& Sons. 1993; 1-35.

[2] Höfte H, Whiteley HR. Insecticidal crystal proteins of Bacillus thuringiensis. Microbiol Rev. 1989; 53: $242-255$. 
[3] Crickmore N, Zeigler DR, Feitelson J, Schnepf HE, Van Rie J, Lereclus D, Baum J, Dean DH. Revision of the nomenclature for the Bacillus thuringiensis pesticidal crystal proteins. Microbiol Mol Biol Rev. 1998; 62: 807813.

[4] Schnepf HE, Crickmore N, Van Rie J, Lereclus D, Baum J, Feitelson J, Zeigler DR, Dean. Bacillus thuringiensis and its pesticidal crystal proteins. Microbiol Mol Biol Rev. 1998; 62: 775-806.

[5] Warren GW, Koziel MG, Mullins MA, Nye GJ, Carr B, Desai WM, Kostochka K, Duck NB, Estruch JJ. Novel pesticidal protein and strains, Patent WO 96/10083, World Intellectual Property Organization. 1996.

[6] Shi Y, Xu W, Yuan M, Tang M, Chen J, Pang Y. Expression of vip1/vip2 genes in Escherichia coli and Bacillus thuringiensis and the analysis of their signal peptides. J Appl Microbiol. 2004; 97: 757-765.

[7] Estruch JJ, Warren GW, Mullins MA, Nye GJ, Craig JA, Koziel MG. Vip3A, a novel Bacillus thuringiensis vegetative insecticidal protein with a wide spectrum of activities against lepidopteran insects. Proc. Natl. Acad. Sci. U. S. A. 1996; 93: 5389-5394.

[8] Jurat-Fuentes JL, Gould FL, Adang MJ. Dual resistance to Bacillus thuringiensis Cry1Ac and Cry2Aa toxins in Heliothis virescens suggests multiply mechanism of resistance. Appl Environ Microbiol. 2003; 69: 5898-5906.

[9] Sayyed AH, Raymond B, Sales Ibiza-Palacios M, Escriche B, Wright DJ. Genetic and biochemical characterization of field-evolved resistance to Bacillus thuringiensis toxin Cry1Ac in the diamondback moth, Plutella xylostella. Appl Environ Microbiol. 2004; 70: 7010-7017.

[10] Boukedi H, Sellami S, Ktari S, Belguith-Ben Hassan N, Tounsi S, Abdelkefi-Mesrati L. Isolation and Characterization of a new Bacillus thuringiensis strain with a promising toxicity against Lepidopteran pests. Microbiol Res. 2016; 186: 9-15.

[11] Abdelkefi-Mesrati L, Tounsi S, Jaoua. Characterization of a novel vip3-type gene from Bacillus thuringiensis and evidence of its presence on a large plasmid. FEMS Microbiol Lett. 2005; 244: 353-358.

[12] Carozzi NB, Kramer VC, Warren GW, Evola S, Koziel M. Prediction of insecticidal activity Bacillus thuringiensis strain by polymerase chain reaction product profiles. Appl Environ Microbiol. 1991; 57: 353-356.

[13] Sambrook J, Frisch EF, Maniatis T. Molecular Cloning: A Laboratory Manual, 2nd ed. Cold New York: Spring Harbor Laboratory, Cold Spring Harbor. 1989.

[14] Travers RS, Martin PAW, Reichelderfer CF. Selective process for efficient isolation of soil Bacillus species. Appl Environ Microbiol. 1987; 53: 1263-1266.

[15] Donovan WP, Donovan JC, Engleman JT. Gene knockout demonstrates that vip3A contributes to the pathogenesis of Bacillus thuringiensis toward Agrotis ipsilon and Spodoptera exigua. J Invertebr Pathol. 2001; 78: 45-51.

[16] Saadaoui I, Al-Thani R, Al-Saadi F, Belguith-Ben Hassan N, Abdelkefi-Mesrati L, Schultz P, Rouis S, Jaoua S. Characterization of Tunisian Bacillus thuringiensis strains with abundance of kurstaki subspecies harbouring insecticidal activities against the lepidopteran insect Ephestia kuehniella. Curr Microbiol. 2010; 61: 541-548.

[17] Laemmli UK. Cleavage of structural proteins during the assembly of the head bacteriophage T4. J Nat. 1970; 227: 680-685.

[18] Abdelkefi-Mesrati L, Boukedi H, Chakroun M, Kamoun F, Azzouz H, Tounsi S, Rouis S, Jaoua S. Investigation of the steps involved in the difference of susceptibility of Ephestia kuehniella and Spodoptera littoralis to the Bacillus thuringiensis Vip3Aa16 toxin. J Invertebr Pathol. 2011; 107: 198-201.

[19] Abdelkefi-Mesrati L, Boukedi H, Dammak-Karray M, Sellami-Boudawara T, Jaoua S, Tounsi S. Study of the Bacillus thuringiensis Vip3Aa16 histopathological effects and determination of its putative binding proteins in the midgut of Spodoptera littoralis. J Invertebr Pathol. 2011; 106: 250-254.

[20] Ben Hamadou-Charfi D, Boukedi H, Abdelkefi-Mesrati L, Tounsi S, Jaoua S. Agrotis segetum midgut putative receptor of Bacillus thuringiensis vegetative insecticidal protein Vip3Aa16 differs from that of Cry1Ac toxin. J. Invertebr. Pathol. 2013; 114: 139-143.

[21] Boukedi H, Ben Khedher S, Hadhri R, Jaoua S, Tounsi S, Abdelkefi-Mesrati L. Vegetative insecticidal protein of Bacillus thuringiensis BLB459 and its efficiency against Lepidoptera. Toxicon. 2017; 129: 89-94.

[22] Venables WN, Smith DM. The R Development Core Team. An Introduction to R. Notes on R: A Programming Environment for Data Analysis and Graphics Version 1.9.1. 2004. 
[23] Wielinga PR, Hamidjaja RA, Ågren J, Knutsson R, Segerman B, Fricker M, Ehling-Schulz M, de Groot A, Burton J, Brooks T, Janse I, van Rotterdam B. A multiplex real-time PCR for identifying and differentiating B. anthracis virulent types. Int J Food Microbiol. 2011; 145: 137-144.

[24] Abdelkefi-Mesrati L, Rouis S, Sellami S, Jaoua S. Prays oleae midgut putative receptor of Bacillus thuringiensis vegetative insecticidal protein Vip3LB differs from that of Cry1Ac toxin. Mol Biotechnol. 2009; 43: 15-19. 